V.S. Grinchenko, O.O. Tkachenko, N.V. Grinchenko

\title{
IMPROVING CALCULATION ACCURACY OF CURRENTS IN CABLE SHIELDS AT DOUBLE-SIDED GROUNDING OF THREE-PHASE CABLE LINE
}

\begin{abstract}
This paper deals with the calculation of currents in shields of single-core cables at double-sided grounding of three-phase cable lines. We consider flat and trefoil cable lines and receive the analytical expressions for RMS currents in the shields of cables. These expressions allow reducing the shield current calculation error to value of $5 \%$. We analyze the known approximate expressions for RMS currents in the shields of cables and represent dependencies of corresponding calculation errors on cable line dimensionless parameters. These dimensionless parameters are determined by the distance between the axes of the cables, the radius and the resistance of shields. References 10, figures 4.
\end{abstract}

Key words: cable line, shield of a cable, shield current, double-sided grounding.

В работе рассмотрена задача расчета токов в экранах одножильных кабелей при двустороннем заземлении трехфазной кабельной линии. Для случаев прокладки кабелей в плоскости и треугольником получены аналитические выражсени для действующих значений токов в экранах, позволяющие ограничить погрешность расчета на уровне $5 \%$ Проведен анализ приближенных выражений для токов в экранах кабелей. Представлены графики зависимостей погрешности приближенных выражений от производных безразмерных параметров кабельной линии, которые определяются расстоянием между осями кабелей, радиусом экранов и их активным сопротивлением. Библ. 10 , рис. 4 . Ключевые слова: кабельная линия, экран кабеля, ток в экране, двустороннее заземление.

Introduction. When laying high-voltage cable power lines (CL), a necessary condition is the grounding of electrically conductive cable shields, one-sided or twosided. The main advantage of single-sided grounding is the absence of longitudinal currents in the shields, which does not violate the thermal mode of the CL and ensures the maximum throughput of the CL. The disadvantage is the induced potential on the shield and, accordingly, the need to install protective devices against overvoltage [1]. When grounding shields at both ends with transposition of shields, longitudinal currents are also absent. However, the complexity and high cost of transposition limits its universal application. The simplest is the double-sided grounding of the cable shields, which provides no surge voltage and does not require the installation of additional protective devices [1]. In this case, the cable screens form closed contours along which the induced longitudinal currents flow [2-4]. On the one hand, this leads to a decrease in the magnetic field of the CL and contributes to solving the problems of the magnetic ecology; on the other hand, currents in the cable shields can disrupt the thermal mode of the CL and lead to a decrease in the line capacity $[5,6]$. Therefore, the calculation of currents in the screens is an actual task.

The analysis of literature sources showed that for the calculation of induced currents in shields with their twosided grounding, different approximate expressions are used. The normative document [7] contains expressions for calculating the currents in the shields when laying cables in the plane and with a triangle. These approximate expressions have a simple form and are used in practice when designing CL. In [8], the problem of thermal losses in cable screens is considered, and expressions for the current values of currents are given. For the case of laying cables in a triangle, the above expression is compact, but for the case of laying in the plane, expression are rather cumbersome. Therefore, to estimate the magnitude of the currents in the screens when laying cables in the plane, use a compact expression for laying with a triangle, assuming the distance between the cables is equal to the mean geometric interphase distance of the CL. In [9], this approach was used to analyze the inductance of threephase CL for arbitrary arrangement of cables.

Approximate expressions are convenient for engineering calculations. However, as shown below, the error in calculating the currents in the shields with the help of approximate expressions can be more than $30 \%$.

The goal of the paper is obtaining expressions for the effective values of currents in cable shields with their two-sided grounding, which makes it possible to limit the calculation error at the level of 5\% with a real spread of the CL parameters.

Calculation of currents in the cable shields. In [10] an analytical model of the magnetic field of a threephase CL with two-sided shielded single-core cables was developed. It is applicable under the following natural assumptions: the distribution of the induced current in the screen of each cable is uniform, and the thickness of the screen is much smaller than its radius. The model makes it possible to calculate the currents in the shields and the distribution of the magnetic induction of the field created by the CL for arbitrary arrangement of its cables. The scatter of the results of calculating the magnetic induction and experimental data $[3,4]$ does not exceed 5\%.

In [10] analytical expressions for the complex amplitudes of currents induced in cable shields with their two-sided grounding are given. Calculating the modulus of these expressions, bringing such terms and dividing by, we obtain expressions for the effective values of the currents in the shields. As variables it is convenient to use the following dimensionless CL parameters:

$$
Q=\frac{\mu_{0} \omega}{2 \pi R^{*}}, \quad \Delta=\frac{s}{r},
$$

where $\omega=2 \pi \cdot 50 \mathrm{~s}^{-1}$ is the frequency of the current; $R^{*}$ is cable length unit length resistance, $\Omega / \mathrm{m} ; s$ is the distance between axes of adjacent cables, $\mathrm{m} ; r$ is the radius of the shield section, $\mathrm{m} ; \mu_{0}=4 \pi \cdot 10^{-7} \mathrm{H} / \mathrm{m}$ is the magnetic constant. 
If the cables are laid in a plane, and the currents in the veins form a system of direct sequence, then the expressions for the current values of the currents in the shields with their bilateral grounding take the following form:

$$
\begin{aligned}
& I_{1}^{\mathrm{sh}}=I \cdot \sqrt{\frac{\left(Q \cdot \ln 2 \Delta \cdot \ln \frac{\Delta^{3}}{2}+\sqrt{3} \cdot \ln 2\right)^{2}+\ln ^{2} 4 \Delta^{3}}{\left(Q \cdot \ln 2 \Delta \cdot \ln \frac{\Delta^{3}}{2}-\frac{3}{Q}\right)^{2}+4 \cdot \ln ^{2} 2 \Delta^{3}}}, \\
& I_{2}^{\mathrm{sh}}=I \cdot \sqrt{\frac{Q^{2} \cdot \ln ^{2} \frac{\Delta^{3}}{2}}{9+Q^{2} \cdot \ln ^{2} \frac{\Delta^{3}}{2}},} \\
& I_{3}^{\mathrm{sh}}=I \cdot \sqrt{\frac{\left(Q \cdot \ln 2 \Delta \cdot \ln \frac{\Delta^{3}}{2}-\sqrt{3} \cdot \ln 2\right)^{2}+\ln ^{2} 4 \Delta^{3}}{\left(Q \cdot \ln 2 \Delta \cdot \ln \frac{\Delta^{3}}{2}-\frac{3}{Q}\right)^{2}+4 \cdot \ln ^{2} 2 \Delta^{3}}},
\end{aligned}
$$

where $I$ is the effective current value in the conductors of the cables.

In the case of an inverse sequence of currents in the conductors, expressions for the currents in the shields of the first and third cables are interchanged in (1).

In the case of laying cables by a triangle, the current values of the currents in the screens with their two-sided grounding are equal to each other $[8,10]$ :

$$
I^{\mathrm{sh}}=I \cdot \sqrt{\frac{Q^{2} \ln ^{2} \Delta}{1+Q^{2} \ln ^{2} \Delta}} .
$$

In [7-9] various approximate expressions are given for calculating the effective values of the currents in the screens when laying cables in the plane. To determine the error of these expressions, we use (1). Quantitatively, the error is defined as follows:

$$
\varepsilon=\sum_{k=1}^{3} \sqrt{\frac{1}{3}\left(1-\frac{I_{k}^{\text {approx }}}{I_{k}^{\text {sh }}}\right)^{2}} \cdot 100 \%
$$

where $I_{k}^{s h}$ is the effective value of current in the $k$-th cable shield calculated by $(1) ; I_{k}^{\text {approx }}$ is the effective value of current in the shield calculated by approximate expressions [7-9].

Analysis of the errors of approximate expressions for currents in shields when laying cables in a plane. In the normative document [7, p. 297] an approximate expression is presented for calculating the currents in the shields when laying cables in the plane. Writing it through $Q$, we get:

$$
I_{k}^{\text {approx }}=I \cdot \sqrt{0.75 \cdot \frac{42.5 \cdot Q^{2}}{\pi^{2}+42.5 \cdot Q^{2}}+0.25 \cdot \frac{25 \cdot Q^{2}}{\pi^{2}+25 \cdot Q^{2}}} .
$$

We use (3) to find the error in calculating the currents with the help of (4). Fig. 1 shows the graphs of the dependences of the relative deviation of $\varepsilon$ from the derivatives of the CL parameters. The curves are plotted for intervals of $Q$ and $\Delta$ values, which are characteristic for $\mathrm{CR}$, calculated for voltages of $45 \div 330 \mathrm{kV}$. Note that the values of $Q$ equal to 0.15 and 0.35 are attained at values of the resistance $R^{*}$ equal to $0.42 \cdot 10^{-3} \Omega / \mathrm{m} \mathrm{и}$ $0.18 \cdot 10^{-3} \Omega / \mathrm{m}$ which in turn are characteristic for shields with cross-sections of $45 \mathrm{~mm}^{2}$ and $105 \mathrm{~mm}^{2}$, respectively.
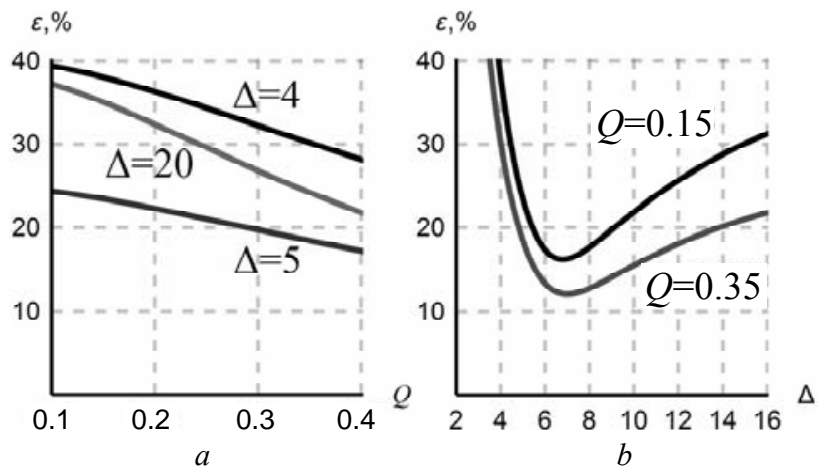

Fig. 1

From the presented graphs it is seen that the error $\varepsilon$ as a whole is determined by the value $\Delta$ (Fig. $1, b)$, and the dependence of $\varepsilon$ on $Q$, i.e. on the active resistance of the shield, can be ignored (Fig. 1,a). From Fig. 1,b it follows that an error of less than $20 \%$ is achieved in a rather narrow range for values of $\Delta$ greater than 5 and less than 10-12. If the distance between axes of adjacent cables is less than 4 or more than 20 screen radii, then the error of application (4) for calculating the currents in shields with their bilateral grounding may exceed $30 \%$.

Using the approach presented in [9, p. 180], to calculate the currents in the screens when laying cables in the plane, one can use expression (2) with $\Delta$ replaced by, where is the geometric mean distance between the cable axes. Then, in terms of $Q$ and $\Delta$, the expression for determining the effective value of the current in the screen of each cable will have the following form:

$$
I_{k}^{\text {approx }}=I \cdot \sqrt{\frac{Q^{2} \cdot \ln ^{2} \Delta \sqrt[3]{2}}{1+Q^{2} \cdot \ln ^{2} \Delta \sqrt[3]{2}}} .
$$

The error in applying this expression can be calculated using (3). The results of the calculation are shown in Fig. 2.
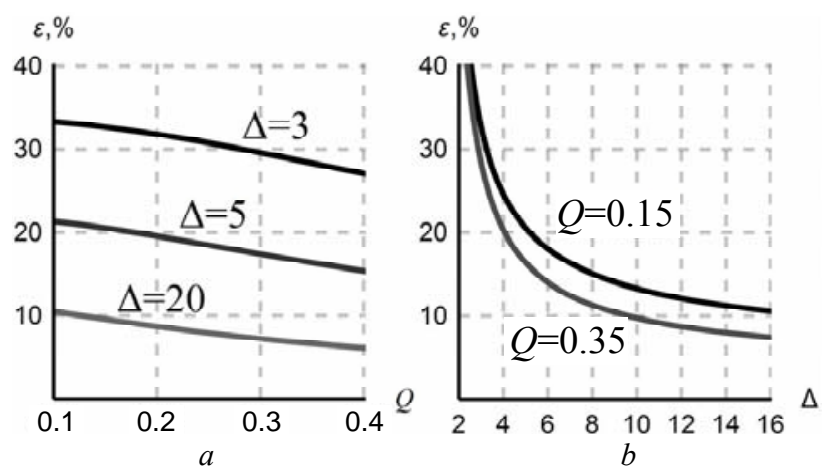

Fig. 2

As in the previous case, the error depends weakly on the parameter Q (Fig. 2,a) and essentially depends on the value of $\Delta$ (Fig. $2, b$ ). The error of $20 \%$ is reached at $\Delta>5$. For $\Delta<3$, the error in applying expression (5) exceeds $30 \%$. 
Expressions for calculating the current values of currents in double-sided earthed shields when laying cables in the plane are also given in [8, p. 227]. In terms of $Q$ and $\Delta$, they can be written as follows:

$$
\begin{aligned}
& I_{1}^{\text {approx }}=I \cdot \sqrt{\frac{0.75 \cdot \frac{Q^{2} \ln ^{2} 2 \Delta}{1+Q^{2} \ln ^{2} 2 \Delta}+0.25 \cdot \frac{Q^{2} \ln ^{2} \frac{\Delta}{\sqrt[3]{2}}}{1+Q^{2} \ln ^{2} \frac{\Delta}{\sqrt[3]{2}}}+\frac{2}{\sqrt{3}} \cdot \frac{Q^{3} \cdot \ln 2 \Delta \cdot \ln \frac{\Delta}{\sqrt[3]{2}} \cdot \ln 2}{\left(1+Q^{2} \ln ^{2} 2 \Delta\right) \cdot\left(1+Q^{2} \ln ^{2} \frac{\Delta}{\sqrt[3]{2}}\right)}}{I_{2}^{\text {approx }}=I \cdot \sqrt{\frac{Q^{2} \ln ^{2} \frac{\Delta}{\sqrt[3]{2}}}{1+Q^{2} \ln ^{2} \frac{\Delta}{\sqrt[3]{2}}}},}} \\
& I_{3}^{\text {approx }}=I \cdot \sqrt{\left.0.75 \cdot \frac{Q^{2} \ln ^{2} 2 \Delta}{1+Q^{2} \ln ^{2} 2 \Delta}+0.25 \cdot \frac{Q^{2} \ln ^{2} \frac{\Delta}{\sqrt[3]{2}}}{1+Q^{2} \ln ^{2} \frac{\Delta}{\sqrt[3]{2}}}-\frac{2}{\sqrt{3}} \cdot \frac{Q^{3} \cdot \ln 2 \Delta \cdot \ln \frac{\Delta}{\sqrt[3]{2}} \cdot \ln 2}{\left(1+Q^{2} \ln ^{2} 2 \Delta\right) \cdot\left(1+Q^{2} \ln ^{2} \frac{\Delta}{\sqrt[3]{2}}\right.}\right)} .
\end{aligned}
$$

Let us investigate the error in calculating the currents with the help of (6). Fig. 3 shows the dependence of the error $\varepsilon$ on $Q$ and $\Delta$ calculated according to (3).

The greatest error is reached at $\Delta=4$, and it does not exceed $15 \%$. At the same time, for $Q>0.25$, the error exceeds the permissible value for engineering calculations of $10 \%$.
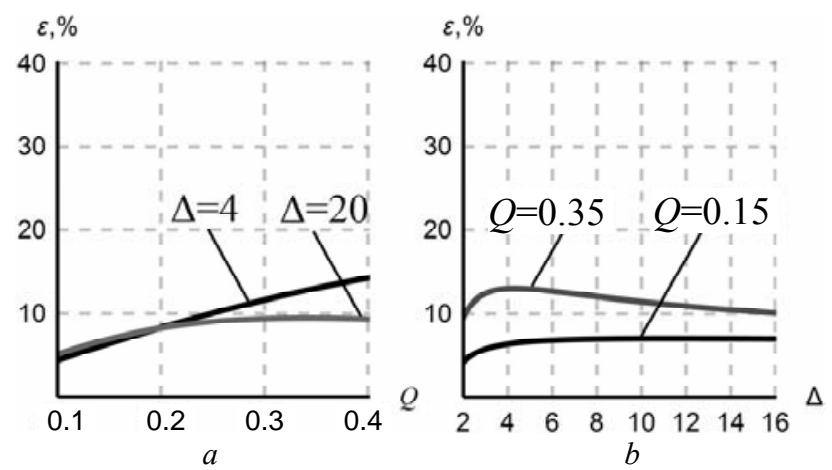

Fig. 3

Analysis of the error of the approximate expression for the currents in the shields when the cables are laid with a triangle. Separately, consider the case of laying cables in a triangle. In the normative document [7, p. 296], in order to calculate the effective currents in two-sided earthed shields, instead of (2) it is recommended to use the following expression:

$$
I^{\text {approx }}=I \cdot \sqrt{\frac{0.0019}{R_{70}^{2}+0.0019}},
$$

where $R_{70}$ is the resistance of the shield of $1 \mathrm{~km}$ of the cable, $\Omega / \mathrm{km}$.

Rewriting it through the dimensionless parameter $Q$, we obtain:

$$
I^{\text {approx }}=I \cdot \sqrt{\frac{4.75 \cdot Q^{2}}{\pi^{2}+4.75 \cdot Q^{2}}} .
$$

Since the effective values of the currents in the screens are equal when the triangle is laid, the error in applying the approximate expression (7) is defined as follows:

$$
\varepsilon=\left|1-\frac{I^{\text {approx }}}{I^{\text {sh }}}\right| \cdot 100 \%,
$$

where $I^{\text {sh }}$ is calculated by (2), and $I^{a p p r o x}$ is calculated by (7).

The graphs of the dependences of $\varepsilon$ on $Q$ and $\Delta$ are shown in Fig. 4. As can be seen from Fig. 4,a, the error varies only slightly with $Q$, which indicates an insignificant effect of the active resistance. From the dependence shown in Fig. 4, $b$ we can conclude that the error of the approximate formula (7) does not exceed $20 \%$ only for $\Delta<2.4$. At the same time, for $\Delta>5$, the error $\varepsilon$ exceeds $50 \%$.
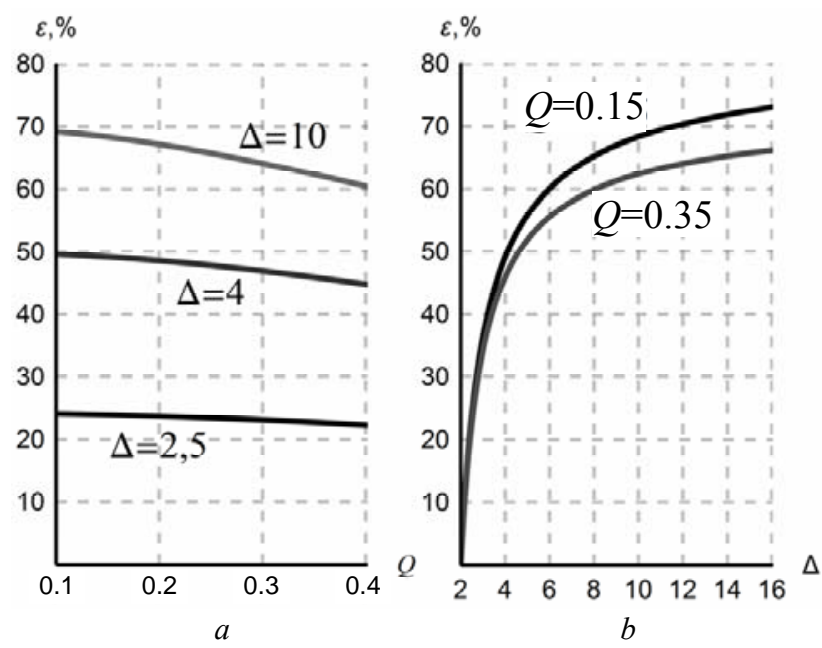

Fig. 4

Thus, when calculating the current values of currents in cable shields for bilateral grounding, it is recommended to use expressions (1) in case of laying cables in the plane and expression (2) in case of laying by triangle.

\section{Conclusions.}

1. Analytical expressions are obtained which, for cases of laying cables in the plane and with a triangle, allow calculating the effective values of currents in the cable shields with an error of $5 \%$ at their are double-sided grounding. 
2. It is established that the error in calculating the effective values of the currents in the shields with the help of approximate expressions known from the literature sources exceeds $30 \%$ in a wide range of parameters of the cable line.

This work was supported by the State Fund for Fundamental Research of Ukraine under grant $\Phi 70 / 18937$.

\section{REFERENCES}

1. Bystrov A.V. Razrabotka metodiki vybora energoeffektivnoi sistemy zazemleniia ekranov odnozhil'nykh silovykh kabelei s izoliatsiei iz sshitogo polietilena na napriazhenie 6-500 kV. Autoref. diss. kand. techn. nauk [The development of selection methodology of energy efficient grounding systems of 6-500 kV XLPE insulated single-core power cable shields. Abstracts cand. tech. sci. diss.]. Moscow, 2014. 20 p. (Rus).

2. Grinchenko V.S. Increase of screening efficiency of technogenic magnetic field of underground high-voltage power cables. Visnik Nacional 'noi' akademii' nauk Ukrai'ni - Herald of the National Academy of Sciences of Ukraine, 2014, no.8, pp. 71-76. (Ukr).

3. Rozov V.Yu., Dobrodeyev P.N., Erisov A.V., Tkachenko A.O. Increasing the efficiency of contour shielding of the magnetic field of high-voltage cable lines. Tekhnichna Elektrodynamika, 2016, no.4, pp. 5-7. (Rus).

4. Rozov V.Yu., Kvytsynskyi A.A., Dobrodeyev P.N., Grinchenko V.S., Erisov A.V., Tkachenko A.O. Study of the magnetic field of three phase lines of single core power cables with two-end bonding of their shields. Electrical engineering \& electromechanics, 2015, no.4, pp. 56-61. (Rus). doi: 10.20998/2074-272X.2015.4.11.

5. Antonets T.Yu., Vepryk Yu.M., Shchebeniuk L.A. Heat tests of power cables with XLPE insulation at direct voltages up to $110 \mathrm{Kv}$. Electrical engineering \& electromechanics, 2015, no.6, pp. 43-46. (Ukr). doi: 10.20998/2074-272X.2015.6.07.

How to cite this article:

Grinchenko V.S., Tkachenko O.O., Grinchenko N.V. Improving calculation accuracy of currents in cable shields at double-sided grounding of three-phase cable line. Electrical engineering \& electromechanics, 2017, no.2, pp. 39-42. doi: 10.20998/2074-272X.2017.2.06.
6. Shchebeniuk L.A., Antonets T.Yu. Investigation of losses in insulation of high-voltage power cables with XLPE insulation. Electrical engineering \& electromechanics, 2016, no.4, pp. 5862. (Ukr). doi: 10.20998/2074-272X.2016.4.08.

7. Pravila ulashtuvannya electroustanovok [Electrical installation regulations]. Kharkiv, Minenergovugillya of Ukraine Publ., 2014. 793 p. (Ukr).

8. Larina E.T. Silovye kabeli $i$ vysokovoltnye kabelnye linii [Power cables and high-voltage cable lines]. Moscow, Energoatomizdat Publ., 1996. 464 p. (Rus).

9. Kalantarov P.L., Tseytlin L.A. Raschet induktivnostey [Inductance calculations]. Leningrad, Energoatomizdat Publ., 1986. 488 p. (Rus).

10. Rozov V.Yu., Tkachenko A.O., Erisov A.V., Grinchenko V.S. Analytical calculation of magnetic field of three-phase cable lines with two-point bonded shields. Tekhnichna Elektrodynamika, 2017, no.2, pp. 13-18. (Rus).

Received 18.01.2017

V.S. Grinchenko ${ }^{1}$, Candidate of Technical Science,

O.O. Tkachenko ${ }^{1}$, Postgraduate Student,

N.V. Grinchenko ${ }^{2}$, Candidate of Technical Science,

${ }^{1}$ State Institution «Institute of Technical Problems of Magnetism of the NAS of Ukraine»,

19, Industrialna Str., Kharkiv, 61106, Ukraine, phone +380572992162 ,

e-mail: vsgrinchenko@gmail.com,oleksandr.tk7@gmail.com

${ }^{2}$ Ukrainian State University of Railway Transport,

7, Feuerbach Sq., Kharkiv, 61050, Ukraine, phone +380 577301055 